\title{
The flank eruption history of Etna (1610-2006) as a constraint on lava flow hazard
}

\author{
Cristina Proietti ${ }^{\star}$, Emanuela De Beni, Mauro Coltelli, Stefano Branca
}

Istituto Nazionale di Geofisica e Vulcanologia, Sezione di Catania, Osservatorio Etneo, Catania, Italy

\author{
Article history \\ Received November 5, 2010; accepted June 30, 2011. \\ Subject classification: \\ Etna, Effusive flank eruptions, Last 400 y geodatabase, Volcanic risk.
}

\section{ABSTRACT}

Data of the flank eruptions of Etna from over the last 400 years were extracted from the new geological map for the lava flow extensions and vent positions, and from the catalogs of historical eruptions for the eruption durations and lava volumes. The partially or widely hidden lava fields on the new geological map were retrieved from older geological maps. The distributions of the eruption durations and lava volumes were analyzed, with the definition of six eruptive classes for use in numerical simulations. The threshold values for the eruption durations and lava volumes were set at 45 days and at $35 \times 10^{6} \mathrm{~m}^{3}$ and $100 \times 10^{6} \mathrm{~m}^{3}$, respectively. A global analysis was performed on the whole volcano to evaluate the recurrence of the classes, and to estimate for each class the ranges, means and standard deviations of the durations, volumes and elevations of the main vent. The same analysis was repeated by subdividing the volcano into three sectors, which were defined on the basis of the distribution of the eruptive fissures over the last $15 \mathrm{ka}$. The classes have different recurrences across these various sectors, and different distributions of volumes, durations and elevations of the main vent. Finally, a lava flow resurfacing map that counts the number of lava flows on each given area of the volcano over the last 400 years was compiled and then normalized.

\section{Introduction}

The volcanic threat is the combination of the hazards (the dangerous or destructive natural phenomena produced by a volcano) and the exposure (the people and property at risk from the volcanic phenomena). Volcanic hazard is the probability that given areas will be affected by potentially destructive volcanic processes [Fournier 1979]. Evaluation of volcanic hazard is generally based on the past eruptive behavior, on the assumption that the previous activity is representative of that in the future [Guest and Murray 1979, Behncke et al. 2005]. Hazard assessment can be supported by the use of computer simulation codes, which are becoming valuable tools for better understanding and forecasting of lava flow emplacement [Vicari et al. 2006].
Mount Etna is a basaltic composite stratovolcano that formed along the Ionian coast of eastern Sicily as a consequence of the complex eruptive history over the last $500 \mathrm{ka}$ [Branca et al. 2008]. As Etna volcano is located in a densely inhabited area, assessing the hazard posed by its eruptions is particularly important, and this can be based on the long record of its activity. The key information for analyzing its flank activity comes from recent revisions of the catalog of its eruptive history [Branca and Del Carlo 2004 , 2005] that provide the durations and volumes of the recorded eruptions. Moreover, geometrical and geographical information on the lava flow fields can be found in eight different datasets:

- Three geological maps: the New Geological Map (NGM) of Etna volcano, which was updated to 2007 [Branca et al. 2011], and the previous geological maps compiled by Waltershausen [1845-59] and Romano et al. [CNR, 1979];

- Orthophotographs extracted from aerial surveys in 1994, 2001 [Coltelli et al. 2007], 2004 [Baldi et al. 2006] and 2005 [Gwinner et al. 2006];

- Lava flow maps reported in Azzaro and Neri [1992].

Eruptions of Etna consist of quasi-continuous activity at summit craters, and quite frequent events along fissures on its flanks [Branca and Del Carlo 2005]. Strombolian activity and periodic lava fountaining episodes, which are often associated with lava flows, frequently occur at the summit craters [Guest 1982, Coltelli et al. 1998, Coltelli et al. 2000, Calvari et al. 2002, Alparone et al. 2003]. In contrast, the flank eruptions take place at intervals of years, and they produce lava effusion that is commonly associated with weak explosive activity [Branca and Del Carlo 2005].

About three millennia of Etna eruptions are documented in historical sources, which represent a unique record for an active volcano [Tanguy 1981, Branca and Del Carlo 2004]. However, the catalog of flank eruptions is complete and accurate only after the mid- $17^{\text {th }}$ century 


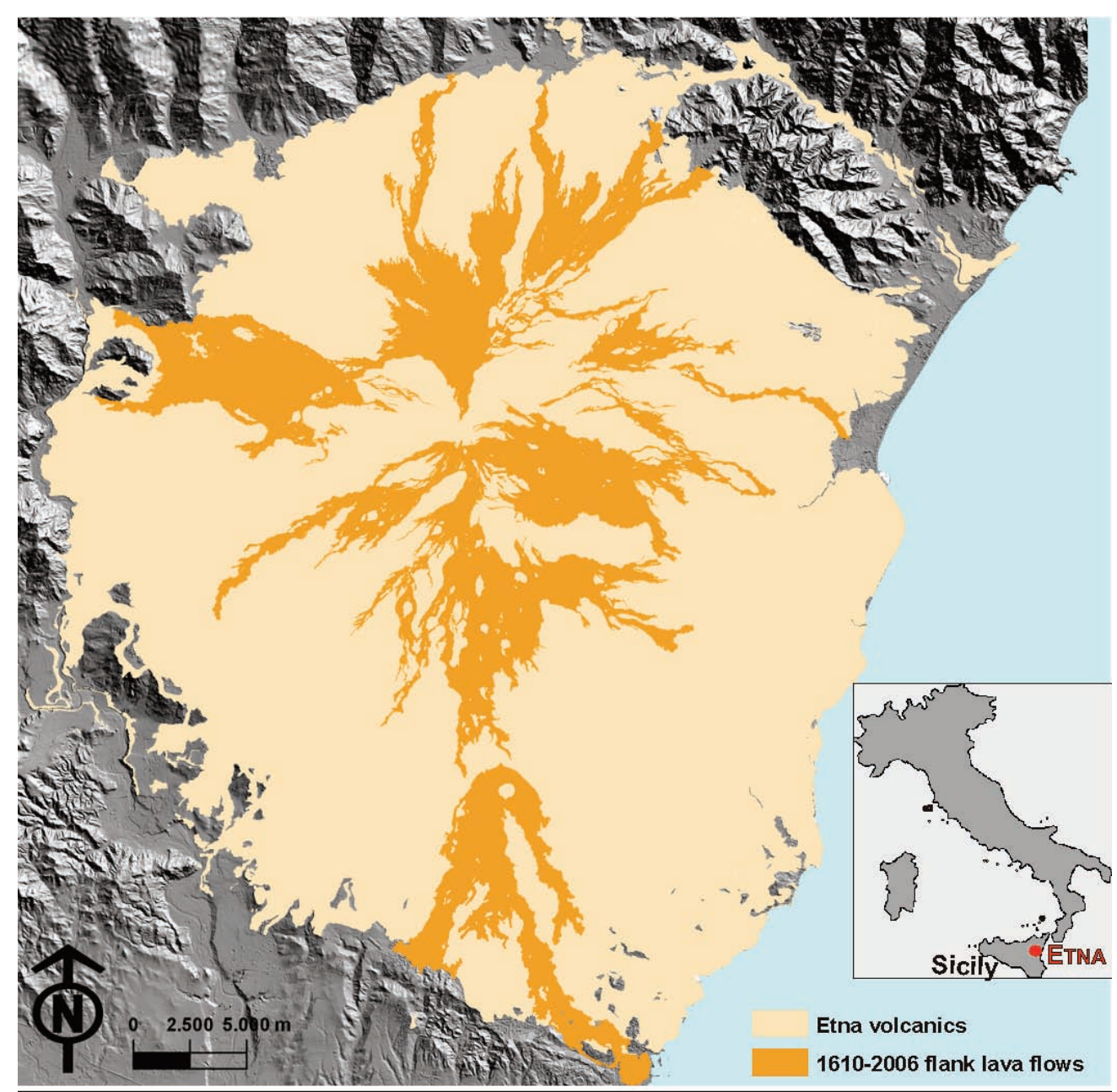

Figure 1. Etna flank lava flows over the last 400 years mapped from the NGM (orange) and Etna volcanics (beige) Inset: location of Mount Etna (red dot) with respect to Sicily and Italy.

[Branca and Del Carlo 2005], although a few events (e.g. $1702,1755)$ are poorly documented, so that the lava flows and eruptive systems that occurred are today irretrievably lost for a valuable study [Tanguy et al. 2007]. The catalog of summit activity is reliable only since the late $19^{\text {th }}$ century [Salvi et al. 2006], although the summit activity poses relatively minor problems in terms of hazard to inhabited areas when compared to the flank eruptions [Duncan et al. 1981, Wadge et al. 1994, Behncke et al. 2005]. Furthermore, the high frequency of summit eruptions implies that most of their products are soon covered by successive volcanics, thus making it difficult to identify and delimit each flow field. Fifty-one summit effusive eruptions over the last 400 years have been retrieved from the historical catalogs [Branca and Del Carlo 2004, 2005], although only 30 lava flow fields can be identified on the three geological maps, and no more than four of these are totally outcropping. As summit eruptions are generally not dangerous for inhabited areas, the evaluation of the hazard at Etna can be limited to flank eruptions, and can be based on the running of several numerical simulations of the lava flow paths, provided that the past eruptive behavior has been analyzed.

This study was devoted to the collection and analysis of all of the available data regarding flank eruptions of Etna that have occurred over the last 400 years (1610-2006). It has allowed the characterization of the distributions of duration and volume, as well as the spatial distributions of these past flank eruptions. These analyses are necessary to define the input of the numerical simulations to be used to compile an Etna hazard map.

\section{Etna flank eruptions over the past 400 years}

This study of the eruptive activity that occurred along the Etna flanks from 1610 to 2006 (Figure 1) was firstly based on an analysis of the historical catalogs [Romano and Sturiale 1982, Branca and Del Carlo 2004, Andronico and Lodato 2005, Behncke et al. 2005, Branca and Del Carlo 2005, Tanguy et al. 2007]. These catalogs furnished information on the eruption durations and on the lava volumes of 67 effusive events, with the volumes of the 2001 and 2006 lava flows retrieved from two studies in the literature [Coltelli et al. 2007, Behncke et al. 2009]. Then, a geodatabase, i.e. a database designed to store, query, and manipulate geographic information and spatial data, was implemented with the ArcGis software (www.esri.com), to store all of the data available for an analysis of the geometry and the location of 
the lava flows during the 67 eruptions (an example of a geodatabase implemented for monitoring Etna eruptions can be found in De Beni and Proietti [2010]). In particular, the two geological maps of Waltershausen [1845-59] and Romano [CNR, 1979], as well as the maps reported in Azzaro and Neri [1992], were digitized and compared with the NGM, to reduce distortions that might arise from the map georeferencing and orthorectifying. Three layers, as polygonal, punctual and linear, were also created inside the geodatabase, for collecting the lava flow fields, their main vents, and the eruptive fissures, respectively.

The analysis of the NGM allowed the identification of the limits and locations of the lava flows during the 67 selected eruptions. Nevertheless, it should be noted that a single eruptive event can produce several lava flows that can be fed by different vents along the same fissure, e.g. the 20022003 eruption on the north-east flank of Etna [Andronico et al. 2005]. In such cases, only the main flows, which are those having the longest duration and that covered the greatest distances from the vent and/or widest areas, were generally considered. Minor lava flows were excluded because they pose little concern for risk reduction purposes, with respect to the main lava flow, and thus they are not specifically relevant when evaluating the spatial distribution of the lava flow fields. In a few cases, the vents that fed lava flows that covered small areas were included, if they threatened inhabited areas and infrastructure, as during the 2001 eruption [Scifoni et al. 2010]. Instead, multiple lava flows were considered when they were on different flanks of the volcano, e.g. during the 1879 , 2001 and 2002-03 eruptions [Branca and Del Carlo 2004, Coltelli et al. 2007, Andronico et al. 2005].

The polygons that define the geometry of the selected lava flow fields were collected in the geodatabase, and the covered area was measured for each polygon and associated to the corresponding record, together with its outcropping area. This parameter qualitatively classifies the present outcrop with respect to the area that each flow field would have originally covered. Indeed, older lava flows might have been covered by more recent eruptions, and thus their limits appear incomplete or they are missing on the NGM although they have a greater outcrop in previous maps. The flow fields can therefore be distinguished as: totally or almost totally outcropping, and partially, widely or totally hidden. Auxiliary information (e.g. eruption year and flow name, eruption style, duration and area, geological map from which the limits were traced, outcropping area, volume, outcropping fracture length, main vent location) is also stored in the attribute table of the polygonal layer of the geodatabase that contains the main lava flows.

Different layers of the geodatabase were also defined for collecting the main vents associated to each lava flow, as well as the eruptive fissures. The attributes associated to the last layer are the fissure length and considerations on their present outcrop, likewise for the lava flow fields. A single vent (called the main vent) was associated to the main lava flows identified on the NGM, and its cartographic coordinates and elevation were measured. The main vent was located along the eruptive fissure, generally where most of the lava was emitted, or at the fissure center, when the lava was uniformly distributed along it. The spatial distribution of the vent relative to the Etna flank eruptions over the last 400 years was necessary for computing the Etna hazard map, as reported in Cappello et al. [2011].

\section{Data analysis}

As the evaluation of volcanic hazard is generally based on the past eruptive behavior, the data available for these 67 Etna flank eruptions over the last 400 years were analyzed. In particular, the distributions of durations and volumes, and the positions of the main vent were investigated, which allowed the definition of a set of eruptive classes that can be used to carry out a number of simulations for the implementing of the Etna hazard map [Cappello et al. 2011]. To increase the information on the spatial distributions of the lava flows as much as possible, all of the available maps were analyzed together with the NGM. In particular, the Waltershausen [1845-59] and Romano [CNR, 1979] geological maps were used to retrieve the lava fields during the $19^{\text {th }}$ century and the $19^{\text {th }}$ and $20^{\text {th }}$ centuries, respectively. The maps reported in Azzaro and Neri [1992] show the lavaflow fields between 1971 and 1991. Finally, the orthophotographs allowed the complete mapping of the 1991-1993 and 2004-2005 lava flows in the Valle del Bove, as well as the 2001 lava flows.

Ten effusive events among the 67 were excluded because their records are not complete, for different reasons. In particular, five lava fields cannot be located: four $(1643,1702$, 1755 and 1918) do not outcrop in any of the maps, and one (1975) cannot be distinguished from another flow field (197577) that occurred soon after in the same area. Moreover, three events (1956, 1964 and 1975-77) have unknown volumes, and two (1682 and 1689) have unknown durations and volumes. Nine eruptions were also excluded because they represent exceptional events, due to their extraordinarily brief (1869, 1908 and 1942) or long (1651-54 and 1614-24) duration, as well as their extremely low $(1883,1968$, and December 1985) or high (1651-54 and 1669) volumes. Duncan et al. [1981] have already indicated that the 1669 eruption was a feature of the activity at the peak over the last 400 years and that its inclusion in the calculations might distort any general predictive model based solely on more normal flank activity. Forty-eight flank eruptions were therefore available for the analysis.

To analyze the spatial distributions of these 48 lava fields, the geometry of those that are partially, widely or totally hidden on the NGM was updated. In particular, their 


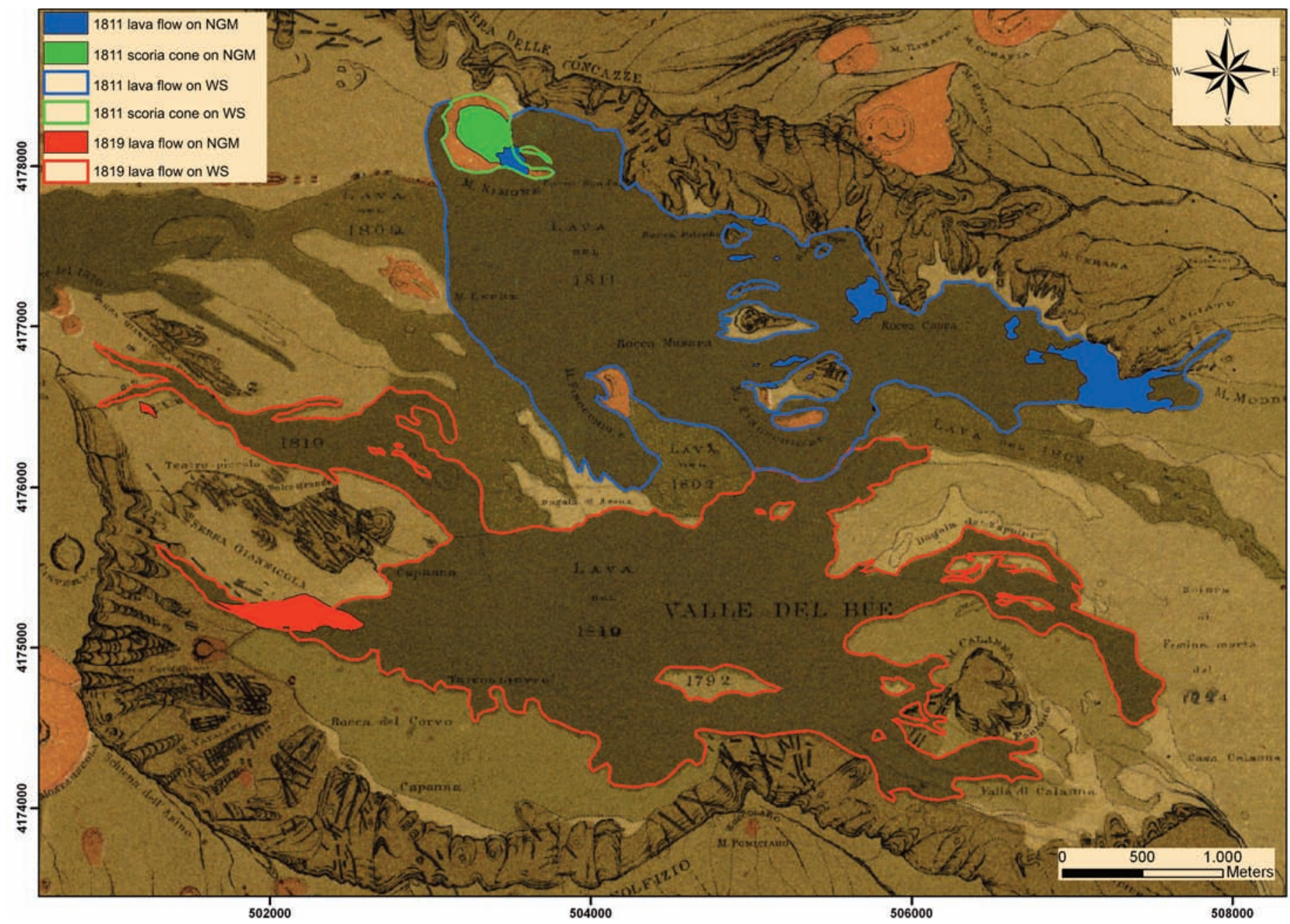

Figure 2. Example of delimitation on the Waltershausen [1845-59] geological map of lava flow fields that are widely hidden on the NGM. The limits of the 1811 and 1819 flow fields defined on the Waltershausen [1845-59] map are drawn as blue and red lines, respectively; the red and blue filled areas represent their portions outcropping on the NGM. Green lines and filled area define the 1811 scoria cone on the Waltershausen [1845-59] map and on the NGM, respectively.

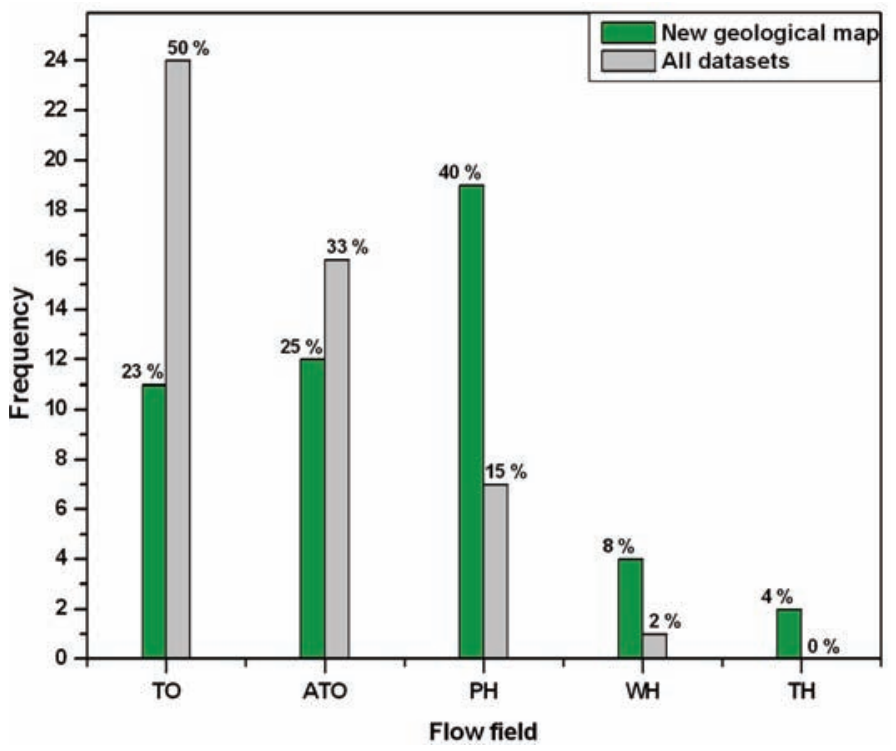

Figure 3. Classification of the lava flow fields over the last 400 year as: totally or almost totally outcropping (TO or ATO), and partially, widely or totally hidden (PH, WH or TH). Green bars refer to the flows defined only on the NGM, while gray bars refer to all of the datasets. The percentages associated with each group are given above the corresponding bar. limits were modified on the basis of the additional data sources, starting from what was still outcropping on the NGM. For example, the 1811 and 1819 lava flow fields (Figure 2) in the Valle del Bove were buried by several eruptions, and so their original geometries were retrieved from the Waltershausen [1845-59] map. Their outcropping areas measured on the NGM are about $0.26 \times 10^{6} \mathrm{~m}^{2}$ and $0.13 \times 10^{6} \mathrm{~m}^{2}$, and respectively corresponds to $5.5 \%$ and $2.2 \%$ of the values measured in the Waltershausen [1845-59] map $\left(4.77 \times 10^{6} \mathrm{~m}^{2}\right.$ and $5.98 \times 10^{6} \mathrm{~m}^{2}$, respectively). After analysis of all the available data sources, the parameters defining the flow outcrop were updated (Figure 3), showing that two hidden flows were retrieved, and that the definition of the planar expansion of the lava flows was improved. Indeed, the percentage of partially, widely or totally hidden flows decreased from $52 \%$ to $17 \%$.

The distributions of the durations and volumes were analyzed through two histograms (Figure 4). The duration histogram (Figure $4 a)$ shows that 26 of the events $(\sim 54 \%$ of the whole dataset) were shorter than 45 days, while the remaining records are quite scattered. The volume 

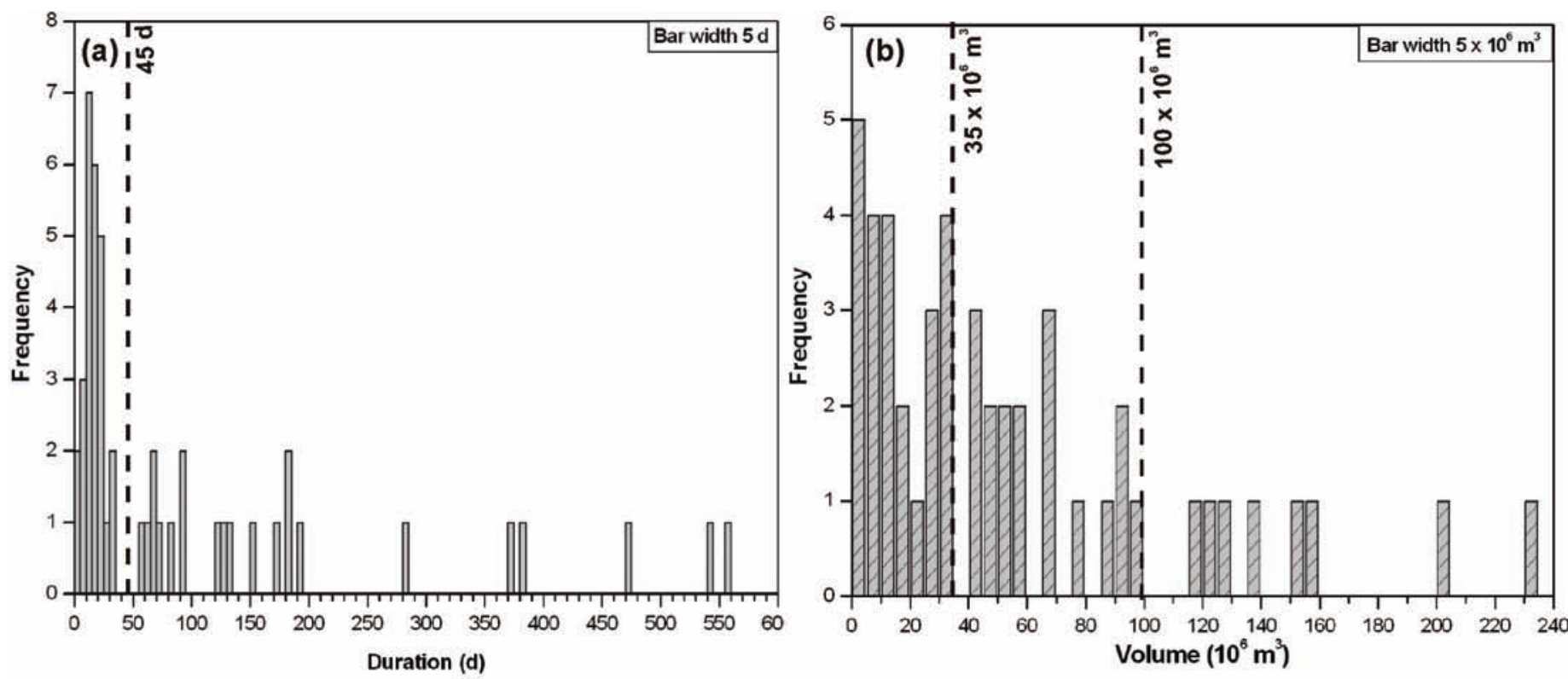

Figure 4. Distributions of the durations (a) and volumes (b) of the 48 selected flank eruptions over the last 400 years. The bar widths are 5 days and $5 \times 10^{6} \mathrm{~m}^{3}$, respectively.

distribution (Figure $4 \mathrm{~b})$ shows that 23 of the events $(\sim 48 \%)$ had a volume $(V)$ lower than $35 \times 10^{6} \mathrm{~m}^{3}$. A second group can be identified by events with $35 \times 10^{6} \mathrm{~m}^{3}<\mathrm{V}<100 \times$ $10^{6} \mathrm{~m}^{3}$, and contains 17 records $(\sim 35 \%)$, with the remaining eight records quite scattered. By combining these considerations of the distributions of the durations and volumes, six eruptive classes (Figure 5a) can be defined:

1) Brief eruptions that emitted low lava volumes (durations $\mathrm{D}<45$ days, volume $\mathrm{V}<35 \times 10^{6} \mathrm{~m}^{3}$ );
2) Brief eruptions that emitted medium lava volumes (D $<45$ days, $\left.35 \times 10^{6} \mathrm{~m}^{3}<\mathrm{V}<100 \times 10^{6} \mathrm{~m}^{3}\right)$;

3) Brief eruptions that emitted high lava volumes $(\mathrm{D}<$ $<45$ days, $\left.\mathrm{V}>100 \times 10^{6} \mathrm{~m}^{3}\right)$;

4) Long eruptions that emitted low lava volumes $(\mathrm{D}>45$ days, $\mathrm{V}<100 \times 10^{6} \mathrm{~m}^{3}$ );

5) Long eruptions that emitted medium lava volumes (D $>45$ days, $35 \times 10^{6} \mathrm{~m}^{3}<\mathrm{V}<100 \times 10^{6} \mathrm{~m}^{3}$ );

6) Long eruptions that emitted high lava volumes ( $\mathrm{D}>$ $>45$ days, $\left.\mathrm{V}>100 \times 10^{6} \mathrm{~m}^{3}\right)$.
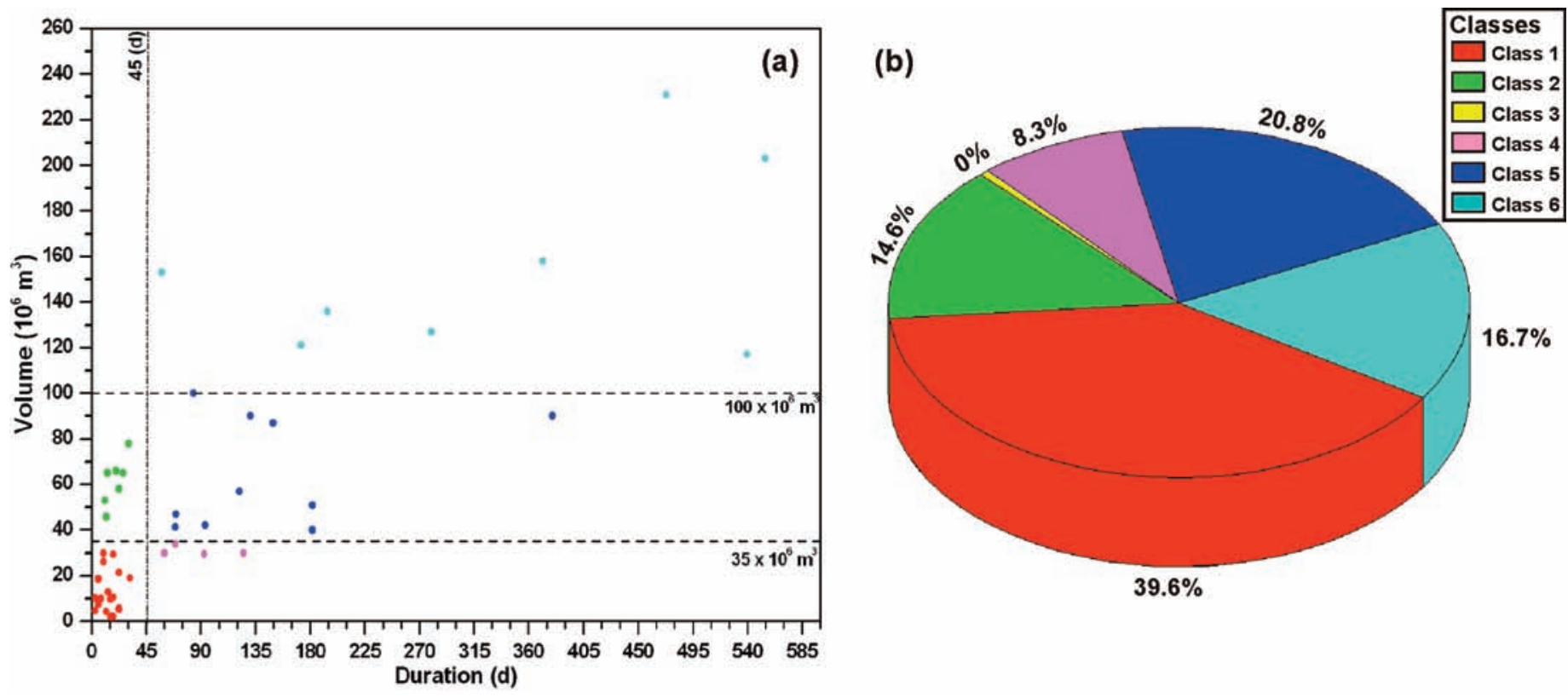

Figure 5. a) Distribution of durations (D) and volumes (V) of the 48 lava flows, and their subdivision into six classes $\left(\right.$ Class 1 : $D<45$ days, $V<35 \times 10^{6}$ $\mathrm{m}^{3}$; Class 2: $\mathrm{D}<45$ days, $35 \times 10^{6} \mathrm{~m}^{3}<\mathrm{V}<100 \times 10^{6} \mathrm{~m}^{3}$; Class 3: $\mathrm{D}<45$ days, $\mathrm{V}>100 \times 10^{6} \mathrm{~m}^{3}$; Class 4 : $\mathrm{D}>45$ days, $\mathrm{V}<35 \times 10^{6} \mathrm{~m}^{3}$; Class 5: $\mathrm{D}>45$ days, $35 \times 10^{6} \mathrm{~m}^{3}<\mathrm{V}<100 \times 10^{6} \mathrm{~m}^{3}$; Class 6: $\mathrm{D}>45$ days, $\mathrm{V}>100 \times 10^{6} \mathrm{~m}^{3}$ ). The dots of the different classes are colored according to the legend reported in (b). b) Pie diagram showing the percentages of the eruptive events belonging to each class. 


\begin{tabular}{|c|c|c|c|c|c|c|c|c|c|c|c|}
\hline & Class & $\begin{array}{l}\text { Number } \\
\text { of events }\end{array}$ & $\begin{array}{c}\mathrm{D} \\
\text { range } \\
\text { (days) }\end{array}$ & $\begin{array}{c}\text { Dmean } \\
\text { (days) }\end{array}$ & $\begin{array}{c}\sigma_{\mathrm{D}} \\
(\text { days })\end{array}$ & $\begin{array}{c}\mathrm{V} \\
\text { range } \\
\left(10^{6} \mathrm{~m}^{3}\right)\end{array}$ & $\begin{array}{l}\text { Vmean } \\
\left(10^{6} \mathrm{~m}^{3}\right)\end{array}$ & $\begin{array}{c}\sigma_{\mathrm{v}} \\
\left(10^{6} \mathrm{~m}^{3}\right)\end{array}$ & $\begin{array}{c}\mathbf{H} \\
\text { range } \\
(\mathbf{m})\end{array}$ & $\begin{array}{l}\text { Hmean } \\
(\mathbf{m})\end{array}$ & $\begin{array}{l}\sigma_{\mathrm{H}} \\
(\mathbf{m})\end{array}$ \\
\hline & All classes & 48 & $3-555$ & 101 & 142 & $2-231$ & 55.8 & 54.3 & $1207-2900$ & 2112 & 393 \\
\hline 1 & $\begin{array}{c}\mathrm{D}<45 \text { days } \\
\mathrm{V}<35 \times 10^{6} \mathrm{~m}^{3}\end{array}$ & 19 & $3-32$ & 15 & 8 & $2-30$ & 12.2 & 9.2 & $1207-2826$ & 2035 & 436 \\
\hline 2 & $\begin{array}{c}\mathrm{D}<45 \text { days } \\
\mathrm{V}=35-100 \times 10^{6} \mathrm{~m}^{3}\end{array}$ & 7 & $11-31$ & 19 & 8 & $46-78$ & 61.5 & 10.4 & $1637-2471$ & 2027 & 319 \\
\hline 3 & $\begin{array}{c}\mathrm{D}<45 \text { days } \\
\mathrm{V}>100 \times 10^{6} \mathrm{~m}^{3}\end{array}$ & 0 & --- & --- & --- & --- & --- & --- & --- & --- & --- \\
\hline 4 & $\begin{array}{c}\mathrm{D}>45 \text { days } \\
\mathrm{V}<35 \times 10^{6} \mathrm{~m}^{3}\end{array}$ & 4 & $60-125$ & 87 & 29 & 29-34 & 31.1 & 2.0 & $1921-2772$ & 2326 & 396 \\
\hline 5 & $\begin{array}{c}\mathrm{D}>45 \text { days } \\
\mathrm{V}=35-100 \times 10^{6} \mathrm{~m}^{3}\end{array}$ & 10 & $69-380$ & 146 & 92 & $40-100$ & 64.5 & 24.2 & $1724-2900$ & 2299 & 386 \\
\hline 6 & $\begin{array}{c}\mathrm{D}>45 \text { days } \\
\mathrm{V}>100 \times 10^{6} \mathrm{~m}^{3}\end{array}$ & 8 & $58-555$ & 331 & 184 & $117-231$ & 155.8 & 44.1 & $1509-2377$ & 2019 & 290 \\
\hline
\end{tabular}

Table 1. Number of events, ranges, means and standard deviations $(\sigma)$ of the durations $(D)$, volumes $(V)$ and elevations of the main vent $(H)$ for each class.

The recurrence of each of the six classes can be seen in the pie diagram in Figure 5b, which shows that class 1 is the most recurrent (39.6\%), followed by class $5(20.8 \%)$, class 6 $(16.7 \%)$ and class $2(14.6 \%)$; class 4 contained the lowest number of events (8.3\%), although finally, class 3 is empty.

The ranges, means and standard deviations of the durations, volumes and elevations of the main vent were also evaluated, for the whole volcano and for the events according to each class (Table 1).

A same analysis was performed by dividing the volcano into three radial sectors that are centered on the summit craters (Figure 6a). The zero and minima of the distribution of fissure orientation, relative to the last $15 \mathrm{ka}$ [Azzaro et al., in press], were considered as delimiting angles of each sector $\left(355^{\circ}-115^{\circ}\right.$ for sector $1 ; 115^{\circ}-225^{\circ}$ for sector $2 ; 225^{\circ}-355^{\circ}$ for sector 3), according to the Duncan et al. [1981] analysis. These authors observed that the sectorial distribution of all of the adventive cones over the last few thousand years is very similar to that of the flank eruptions between 1537 and 1974, thus strongly implying that the distribution remains
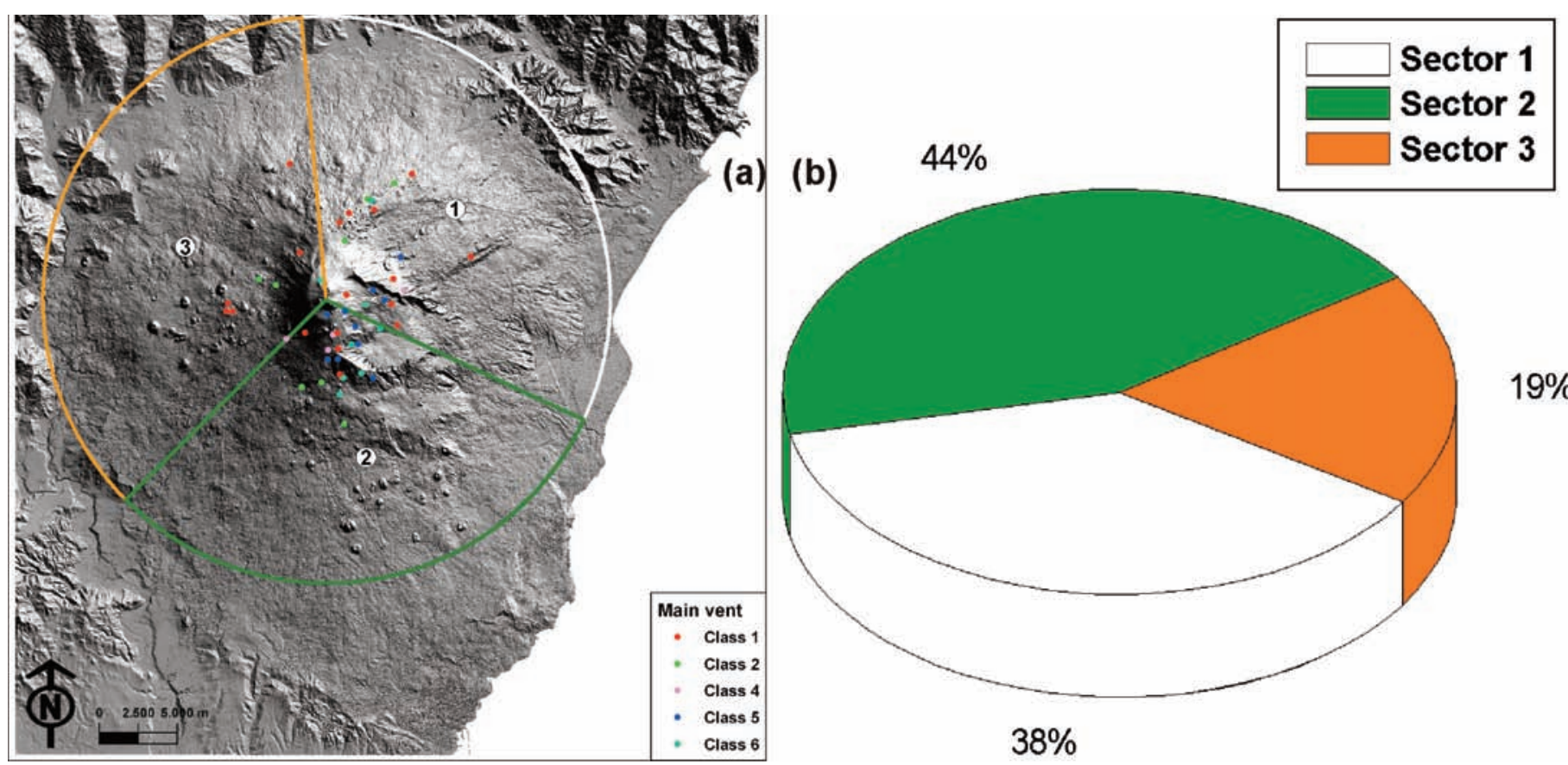

Figure 6. a) Subdivisions of the Etna volcano edifice into three sectors, and classification of the main vents on the basis of the six eruptive classes. b) Pie diagram showing the percentages of the vents located in each sector. 


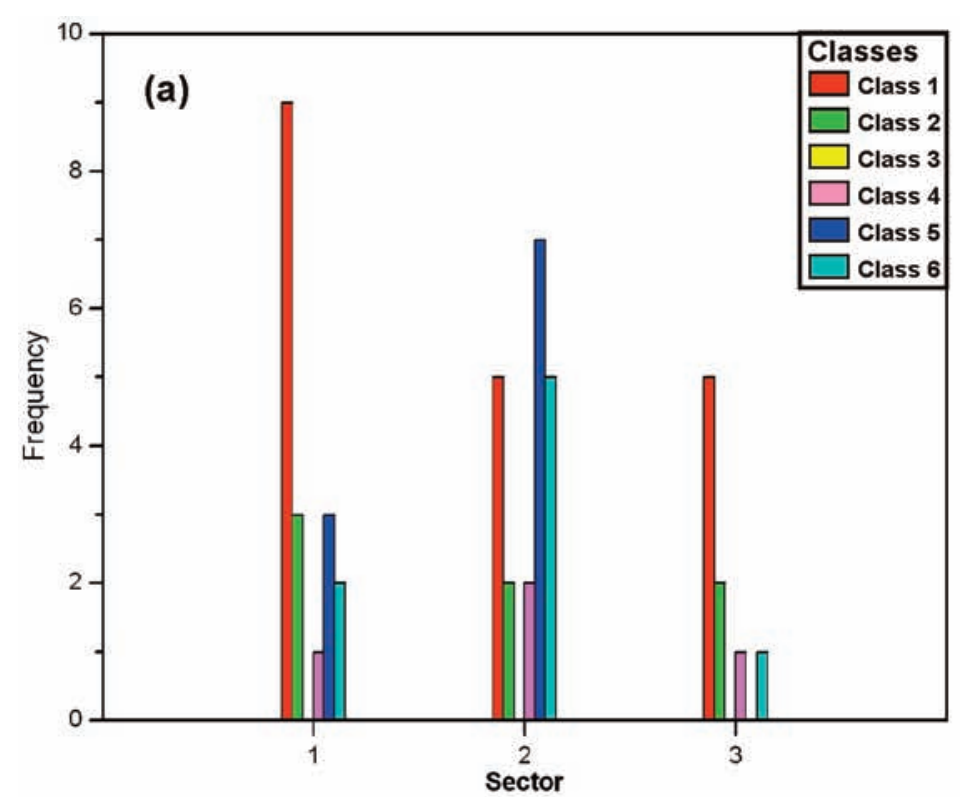

(c)

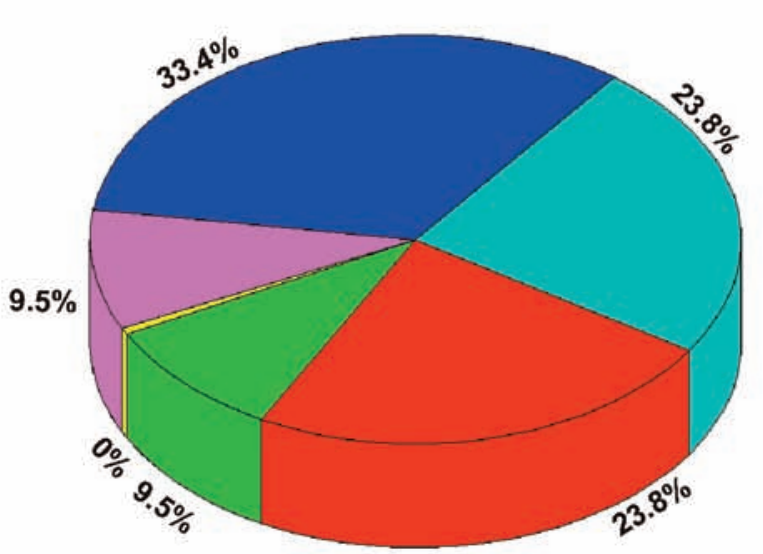

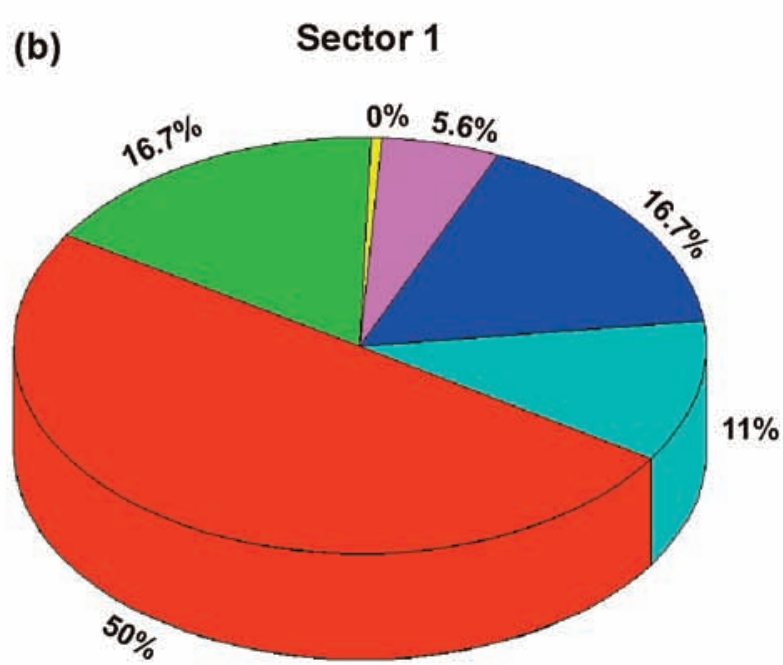

(d) Sector 3

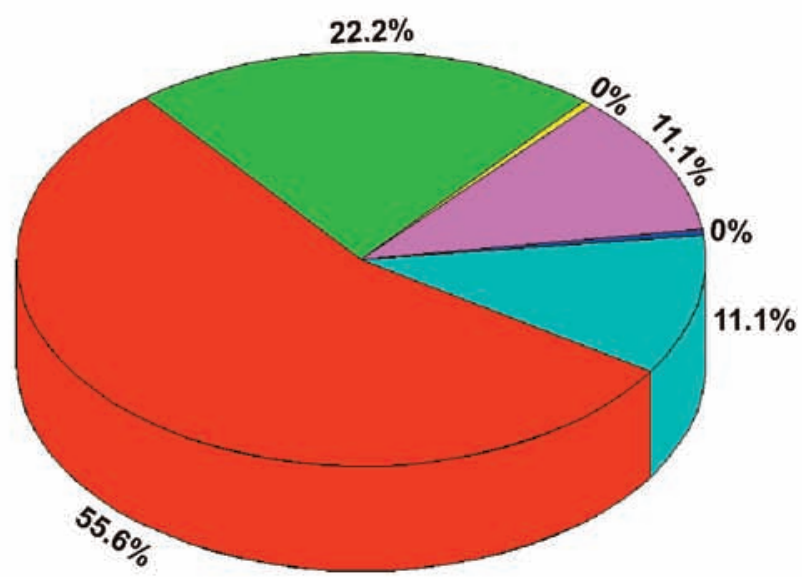

Figure 7. a) Distributions of the six classes in the three sectors into which Etna was divided. The legend refers to all of the panels. (b-d) Pie diagrams showing the distributions of the six classes, as: sector 1 (b), sector 2 (c) and sector 3 (d).

fairly constant over a time scale of hundreds to thousands of years. The sectorial analysis presented here shows that most of the flank eruptions over the last 400 years occurred in sectors 2 and 1 (Figure 6b), which include the south and north-east rifts, respectively. The frequency of the six classes on the three sectors was analyzed and is shown in Figure 7 , which allows the identification of the most recurrent class, which was different for the various sectors. Class 1, i.e. that containing brief eruptions that emitted low lava volumes, was confirmed as having the highest number of events in sectors 1 and 3 , where it represents $50.0 \%$ and $55.6 \%$ of the events, respectively (Figure 7b, d). Class 5, i.e. long eruptions that emitted medium lava volume, was the most recurrent $(33.4 \%)$ in sector 2 (Figure $7 \mathrm{c}$ ). It should also be noted that in sector 2, which coincides with the densest inhabited slope of Mount Etna, class 6 events (long eruptions that emitted large lava volumes) have a recurrence of $23.8 \%$, as does class 1 . The ranges, means and standard deviations of the durations, volumes, and main vent elevations were then evaluated for each sector, for all of the events, and for the most recurrent classes (Table 2). This analysis shows that class 1 has different ranges and means in sectors 1 and 3. The same behavior can be seen when looking at the results of all of the events in each sector.

\section{Resurfacing map of the flank lava flows}

A resurfacing map was also constructed that shows how many times each point of the surface of Etna (in practice each pixel of the DEM adopted for the simulations) has been covered by a lava flow field over the last 400 years. To retrieve as much information as possible, the smaller lava flows that occurred during events that produced multiple flows and that were excluded when defining the vent positions were now taken into account, giving a total of 97 flow field limits. The resurfacing map (Figure 8a) shows that the more frequently covered areas are the Valle del Bove, as well as the south flank, and that the north-east rifts were relatively active. Then the map was normalized by dividing 


\begin{tabular}{|c|c|c|c|c|c|c|c|c|c|c|c|c|}
\hline & Sector & Class & $\begin{array}{l}\text { Number } \\
\text { of events }\end{array}$ & $\begin{array}{c}\mathrm{D} \\
\text { range } \\
\text { (days) }\end{array}$ & $\begin{array}{c}\mathrm{D} \\
\text { mean } \\
\text { (days) }\end{array}$ & $\begin{array}{c}\sigma_{\mathrm{D}} \\
(\text { days })\end{array}$ & $\begin{array}{c}\mathrm{V} \\
\text { range } \\
\left(10^{6} \mathrm{~m}^{3}\right)\end{array}$ & $\begin{array}{c}\mathrm{V} \\
\text { mean } \\
\left(10^{6} \mathrm{~m}^{3}\right)\end{array}$ & $\begin{array}{c}\sigma_{\mathrm{v}} \\
\left(10^{6} \mathrm{~m}^{3}\right)\end{array}$ & $\begin{array}{c}\mathbf{H} \\
\text { range } \\
(\mathbf{m})\end{array}$ & $\begin{array}{c}\mathbf{H} \\
\text { mean } \\
(\mathbf{m})\end{array}$ & $\begin{array}{r}\sigma_{\mathrm{H}} \\
(\mathbf{m})\end{array}$ \\
\hline \multirow{3}{*}{1} & All & --- & 18 & $3-372$ & 62 & 94 & $2-158$ & 47.1 & 47.0 & $1207-2826$ & 2082 & 380 \\
\hline & 1 & $\begin{array}{c}\mathrm{D}<45 \text { days } \\
\mathrm{V}<35 \times 10^{6} \mathrm{~m}^{3}\end{array}$ & 9 & $3-18$ & 12 & 5 & $2-29.4$ & 13.2 & 8.8 & $1207-2826$ & 2065 & 457 \\
\hline & All & --- & 21 & $10-555$ & 145 & 156 & $4-231$ & 72.6 & 62.6 & $1509-2900$ & 2258 & 379 \\
\hline \multirow{2}{*}{2} & 1 & $\begin{array}{c}\mathrm{D}<45 \text { days } \\
\mathrm{V}<35 \times 10^{6} \mathrm{~m}^{3}\end{array}$ & 5 & $10-23$ & 18 & 7 & $4-30$ & 13.4 & 11.7 & $1829-2754$ & 2289 & 368 \\
\hline & 5 & $\begin{array}{c}\mathrm{D}>45 \text { days } \\
\mathrm{V}=35-100 \times 10^{6} \mathrm{~m}^{3}\end{array}$ & 7 & $69-380$ & 144 & 111 & $40-100$ & 64.3 & 27.4 & $1908-2900$ & 2420 & 369 \\
\hline \multirow{3}{*}{3} & 6 & $\begin{array}{c}\mathrm{D}>45 \text { days } \\
\mathrm{V}>100 \times 10^{6} \mathrm{~m}^{3}\end{array}$ & 5 & $173-555$ & 335 & 171 & $121-231$ & 164 & 50.0 & $1509-2293$ & 1949 & 296 \\
\hline & All & --- & 9 & $3-540$ & 79 & 174 & $2-117$ & 33.9 & 37.4 & $1390-2900$ & 1950 & 519 \\
\hline & 1 & $\begin{array}{c}\mathrm{D}<45 \text { days } \\
\mathrm{V}<35 \times 10^{6} \mathrm{~m}^{3}\end{array}$ & 5 & $3-328$ & 15.2 & 11.5 & $2-19$ & 9.4 & 8.7 & $1390-2243$ & 1727 & 314 \\
\hline
\end{tabular}

Table 2. Number of events, ranges, means and standard deviations $(\sigma)$ of durations $(D)$, volumes $(V)$ and elevations of the main vent $(H)$ for all the events and the most recurrent classes in each sector.

it by 97 , the total number of flow fields identified. The normalized resurfacing map (Figure $8 \mathrm{~b}$ ) counts how many times a pixel was covered with respect to the total number of lava flows, and it represents the only quantitative information available for the description of the spatiotemporal evolution of these Etna flank eruptions. It should therefore be considered in the validation processes of lava flow hazard maps that are implemented during the LAVA project.

\section{Discussion and conclusions}

This study analyses the Etna flank eruptions over the last 400 years on the basis of data collected from historical catalogs and geological maps. A geodatabase was implemented for the collection of all of the information available for each eruption; e.g. the georeferenced flow limits (geographic records) and the geological maps on which they were drawn, the definition of the present flow outcrop, the flow areas and the information collected from historical
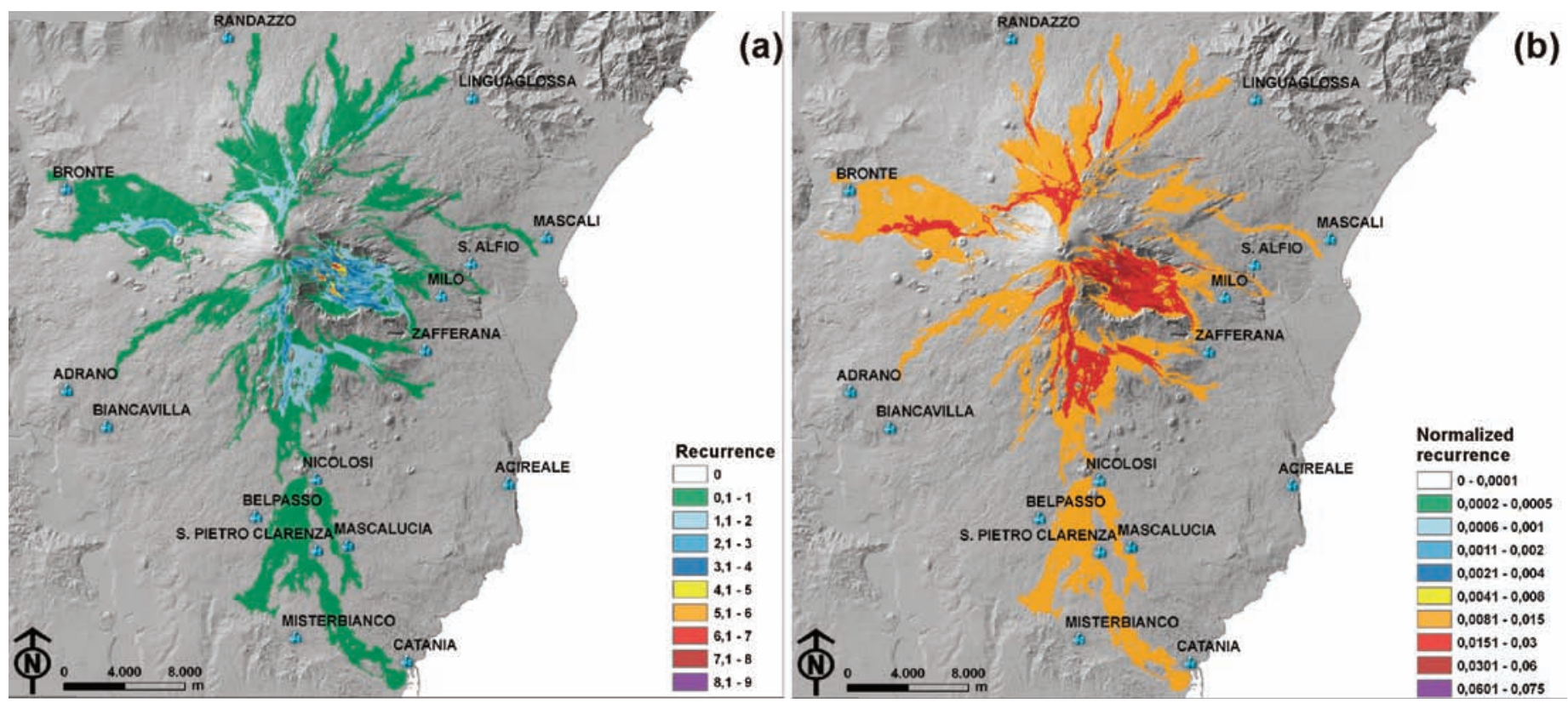

Figure 8. a) Resurfacing map of all of the minor and main lateral lava flows that occurred between 1610 and 2006. b) Normalized resurfacing map. 
catalogs; i.e. eruption durations and lava volumes. The connection of the information derived from different data sources has facilitated the carrying out of the main tasks of this study; namely, the definition of the eruptive classes and the evaluation of the Etna resurfacing map.

A classification based on the durations-volumes of the main lava flows over the last 400 years is presented, with 45 days and $35 \times 10^{6} \mathrm{~m}^{3}$ and $100 \times 10^{6} \mathrm{~m}^{3}$ set as the thresholds of the durations and volumes, respectively. Nevertheless, the analysis shows that five classes are sufficient to include all of the eruptions considered because class 3 (short durations and high volume eruptions) is empty, while class 4 (long durations and low volume eruptions) is poorly represented.

To explain the results obtained for classes 3 and 4, it should be taken into account that two effects control the rates and durations of magma discharges: the balance between the driving and the lithostatic pressures, and the thermal evolution of the magma and the host rock. As an eruption continues, the driving pressure gradually decreases, and it can reduce the flow rate [Bruce and Huppert 1990]. The effect of the driving pressure, and in particular of the de-pressurization of the magma source, is mainly due to relaxation of the reservoir (elastic contraction of the magma body), which was first studied by Wadge [1981]. He analyzed effusion rate trends for various volcanoes, among which there was Mount Etna, and he identified a two-phase trend: "waxing", as characterized by a rapidly increasing flow rate, followed by "waning", a longer period in which the flow rate decreases exponentially. He also observed that the maximum effusion rate is directly proportional to the magma overpressure. When looking at the effusive events analyzed here, a long waning phase might have been responsible for high volume eruptions $\left(\mathrm{V}>100 \times 10^{6} \mathrm{~m}^{3}\right)$, and indeed, these generally had durations longer than 170 days, which corresponds to mean effusion rates lower than $6 \mathrm{~m}^{3} / \mathrm{s}$. This quite low value suggests that most of the eruption could have been characterized by stable and low discharge that was related to a long equilibrium phase between the internal pressure of the dike and the lithostatic pressure which, together with the lava cooling, tend to close the dike. Otherwise, the early end of brief eruptions ( $<45$ days) was probably due to internal dike pressure that was not sufficient to keep the dike open. Moreover, an eruption shorter than 45 days would have a lava volume higher than $100 \times 10^{6} \mathrm{~m}^{3}$ only if its mean effusion rate was higher than $26 \mathrm{~m}^{3} / \mathrm{s}$. Such a high mean effusion rate (total volume divided by total duration) was observed only for eruptions with durations of less than 31 days, which are thus characterized by relatively short waning phases. Finally, as the peak effusion rate is proportional to the initial driving pressure of the reservoir [Wadge, 1981], and as the effusion rate decreases rapidly during the waning phase, a lava volume as high as $100 \times 10^{6}$ $\mathrm{m}^{3}$ cannot be emitted during brief eruptions ( $\mathrm{D}<45$ days). For these reasons, over the last 400 years Etna did not produce eruptive events that belong to class 3 (short durations and high volumes eruptions). Class 4 (long durations and low volume eruptions) is poorly represented for a similar reason: to have a long duration, the internal lava pressure should be high enough to keep the dike open, and this more commonly resulted in medium-high lava volumes, and thus to eruptive events that belong to classes 5 or 6 .

After defining the eruptive classes, two different analyses were performed: a global analysis in the whole volcano, and a sectorial one that considered three radial sectors centered on the summit craters. The recurrence of each class was analyzed through pie diagrams (Figure 7), which show that for the whole volcano, most of the eruptions considered (39.6\%) belong to class 1 (short durations and low volumes). This was also confirmed when looking at the sectorial analysis in sectors 1 and 3. Sector 2, coinciding with the southern Etna flank, mainly contains (33.4\%) class 5 events (long durations and medium volumes). This sector also has a higher frequency (23.8\%) of class 6 events (long durations and high volumes) with respect to the whole volcano $(16.7 \%)$. Moreover, class 6 has the same frequency as class 1 . Taking into account that sector 2 coincides with the most inhabited area of the volcano, the corresponding hazard for this sector should be more carefully assessed. The results obtained also suggest that the south-east rift is the area that has most frequently been affected by magma intrusions since 1610. The ranges, means and standard deviations of the volumes, durations and elevations of the main vent were then evaluated for each class, for the whole volcano (Table 1), as well as for the most recurrent classes, on the three sectors (Table 2). The means can be considered as the representative values to be assigned to each class, while the standard deviations show the data dispersions. By assuming that the future behavior of Etna will be the same as in the recent past, this analysis furnishes the input parameters (duration and volume) to be used in simulations for compiling an Etna hazard map. Different representative values should be considered in the three sectors, because each class has different ranges, means and standard deviations of the volumes, durations and elevations of the main vent.

Finally, the resurfacing maps (Figure 8) allow the evaluation that the areas that have been mostly invaded by lava flows are the Valle del Bove and the south flank. As a probabilistic representation of Etna flank eruptions, the normalized resurfacing map can be compared with the hazard maps produced during the LAVA project, as support in their validation.

Acknowledgements. This study was supported by the Department of Civil Protection, project 2007-2009 V3 LAVA. The authors would like to thank the two anonymous referees and M. Pompilio for the useful reviews that have greatly improved the manuscript. 


\section{References}

Alparone, S., D. Andronico, L. Lodato and T. Sgroi (2003). Relationship between tremor and volcanic activity during the southeast crater eruption on Mount Etna in early 2000, J. Geophys. Res., 108, 2241; doi: 10.1029/2002JB001866.

Andronico, D. and L. Lodato (2005). Effusive activity at Mount Etna volcano (Italy) during the $20^{\text {th }}$ century: a contribution to volcanic hazard assessment, Nat. Hazards, 36, 407-443.

Andronico, D., S. Branca, S. Calvari, M.B. Burton, T. Caltabiano, R.A. Corsaro, P. Del Carlo, G. Garfi, L. Lodato, L. Miraglia, F. Murè, M. Neri, E. Pecora, M. Pompilio, G. Salerno and L. Spampinato (2005). A multi-disciplinary study of the 2002-03 Etna eruption: insights into a complex plumbing system, B. Volcanol., 67, 314-330.

Azzaro R. and M. Neri (1992). L' attività eruttiva dell'Etna nel corso del ventennio 1971-1991. Primi passi verso la costituzione di un data-base relazionale, CNR IIV Open File Report, 3, 46 pp.

Azzaro, R., S. Branca, M. Coltelli and K. Gwinner. The volcanotectonic map of Etna volcano, Ital. J. Geosci., in press.

Baldi, P., E. Bernardo, M. Coltelli, M. Fabris, M. Marsella, C. Proietti and A. Sonnessa (2006). La fotogrammetria digitale applicata in aree vulcaniche: l'area sommitale del monte Etna, In: Atti del Convegno ASITA 2006, 10 ${ }^{a}$ Conferenza Nazionale delle Associazioni Scientifiche per le Informazioni Territoriali e Ambientali (Bolzano 14-17 novembre 2006), Roma, 149-154.

Behncke, B., M. Neri and A. Nagay (2005). Lava flow hazard at Mount Etna (Italy): new data from a GIS-based study, Geol. Soc. Am. Special Papers, 396, 189-208.

Behncke, B., S. Falsaperla and E. Pecora (2009). Complex magma dynamics at Mount Etna revealed by seismic, thermal, and volcanological data, J. Geophys. Res., 114, B03211; doi: 10.1029/2008JB005882.

Branca, S. and P. Del Carlo (2004). Eruptions of Mt Etna during the past 3,200 years: a revised compilation integrating the historical and stratigraphic records, In: A. Bonaccorso, S. Calvari, M. Coltelli, C. Del Negro and S. Falsaperla (eds.), Mount Etna volcano laboratory, Geophysical Monograph Series, AGU, Washington, 143, 1-27.

Branca, S. and P. Del Carlo (2005). Types of eruptions of Etna volcano AD 1670-2003: implications for short-term eruptive behavior, B. Volcanol., 67, 732-742.

Branca, S., M. Coltelli, E. De Beni and J. Wijbrans (2008). Geological evolution of Mount Etna volcano (Italy) from earliest products until the first central volcanism (between 500 and $100 \mathrm{ka}$ ago) inferred from geochronological and stratigraphic data, Int. J. Earth Sci. (Geol. Rundsch.), 97, 135-152.

Branca S., M. Coltelli, G. Groppelli and F. Lentini (2011). Geological map of Etna volcano, 1:50,000 scale, Ital. J. Geosci., 130 (3), 265-291; doi: 10.3301/IJG.2011.15.
Bruce, P. M. and H.E. Huppert (1990). Solidification and melting along dykes by the laminar flow of basaltic magma, In: M.P. Ryan (ed.), Magma transport and storage, Chichester, John Wiley and Sons Ltd., 87-101.

Calvari, S., M. Neri and H. Pinkerton (2002). Effusion rate estimations during the 1999 summit eruption on Mt. Etna, and growth of two distinct lava flow fields, J. Volcanol. Geoth. Res., 119, 107-123.

Cappello, A., A. Vicari and C. Del Negro (2011). Retrospective validation of a lava-flow hazard map for Mount Etna volcano, Annals of Geophysics, 54 (5), 634-640 (this issue).

CNR, Consiglio Nazionale delle Ricerche (1979). Geological map of Mount Etna, 1:50,000 scale, Progetto Finalizzato Geodinamica.

Coltelli, M., M. Pompilio, P. Del Carlo, S. Calvari, S. Pannucci and V. Scribano (1998). Mt Etna - 1993-95 eruptive activity, Acta Vulcanologica, 10, 141-148.

Coltelli, M., P. Del Carlo and M. Pompilio (2000). Etna: Eruptive activity in 1996, Acta Vulcanologica, 12, 63-67.

Coltelli, M., C. Proietti, S. Branca, M. Marsella, D. Andronico and L. Lodato (2007). Analysis of the 2001 lava flow eruption of Mt. Etna from 3D mapping, J. Geophys. Res., 112, F02029; doi: 10.1029/2006JF000598.

De Beni, E. and C. Proietti (2010). Un geodatabase a supporto della mappatura sineruttiva di colate laviche al monte Etna, Rapporti tecnici INGV, 165, 16 pp.; available at http: / / istituto.ingv.it/1-ingv/produzione-scientifica/ rapporti-tecnici-ingv

Duncan, A.M., D.K. Chester and J.E. Guest (1981). Mount Etna volcano: environmental impact and problems of volcanic prediction, Geogr. J., 147 (2), 164-178.

Fournier, E.M. (1979). Objectives of volcanic monitoring and prediction, J. Geol. Soc. London, 136, 321-326.

Guest, J.E. and J.B. Murray (1979). An analysis of hazard from Mount Etna volcano, J. Geol. Soc. London, 136, 347-354.

Guest, J.E. (1982). Styles of eruption and flow morphology on Mount Etna, in Mt. Etna volcano: A Review of the Recent Earth Science Studies, Memorie della Società Geologica Italiana, 23, 49-73.

Gwinner, K., M. Coltelli, J. Flohrer, R. Jaumann, K.D. Matz, M. Marsella, T. Roatsch, F. Scholten and F. Trauthan (2006). The HRSC-AX Mt. Etna project: High-resolution orthoimages and $1 \mathrm{~m}$ DEM at regional scale, In: ISPRS Commission I Symposium (Paris, France, 3-6 July 2006), vol. 36, part 1, T05-23.

Romano, R. and C. Sturiale (1982). The historical eruptions of Mt. Etna, In: R. Romano (ed.), Mount Etna Volcano, Memorie della Società Geologica Italiana, 23, 75-97.

Salvi, F., R. Scandone and C. Palma (2006). Statistical analysis of the historical activity of Mount Etna, aimed at the evaluation of volcanic hazard, J. Volcanol. Geoth. Res., 154, 159-168. 
Scifoni, S., M. Coltelli, M. Marsella, C. Proietti, Q. Napoleoni, A. Vicari and C. Del Negro (2010). Mitigation of lava flow invasion hazard through optimized barrier configuration aided by numerical simulation: the case of the 2001 Etna eruption, J. Volcanol. Geoth. Res., 192, 16-26.

Tanguy, J.C. (1981). Les éruptions historiques de l'Etna: chronologie et localisation, B. Volcanol., 44, 585-640.

Tanguy, J.C., M. Condomines, M. Le Goff, V. Chillemi, S. La Delfa and G. Patanè (2007). Mount Etna eruptions of the last 2,750 years: revised chronology and location through archeomagnetic and ${ }^{226} \mathrm{Ra}-{ }^{230} \mathrm{Th}$ dating, B. Volcanol., 70, 55-83.

Vicari, A., A. Herault, C. Del Negro, M. Coltelli, M. Marsella and C. Proietti (2006). Modeling of the 2001 lava flow at Etna volcano by a cellular automata approach, Environ. Modell. Softw., 20, 1-7; doi: 10.1016/j.envsoft.2006.10.005.

Wadge, G. (1981). The variation of magma discharge during basaltic eruptions, J. Volcanol. Geoth. Res., 11, 139-168.

Wadge, G., P.A.V. Young and I.J. McKendrick (1994). Mapping lava flow hazards using computer simulation, J. Geophys. Res., 99, 489-504.

Waltershausen, W.S. (1845-59). Atlas des Aetna, Berlin, Göttingen, Weimar.

\footnotetext{
${ }^{\star}$ Corresponding author: Cristina Proietti, Istituto Nazionale di Geofisica e Vulcanologia, Sezione di Catania, Catania, Italy; email: cristina.proietti@ct.ingv.it.

(C) 2011 by the Istituto Nazionale di Geofisica e Vulcanologia. All rights reserved.
} 